BMJ Open

Sport \&

Exercise

Medicine

\section{Preseason aerobic and anaerobic tests for prediction of alpine skiing performance: a molecular perspective}

To cite: Koller A,

Schobersberger W. Preseason aerobic and anaerobic tests for prediction of alpine skiing performance: a molecular perspective. BMJ Open Sport \& Exercise Medicine 2019;5:e000510. doi:10.1136/ bmjsem-2019-000510

Accepted 24 February 2019

Check for updates

C) Author(s) (or their employer(s)) 2019. Re-use permitted under CC BY-NC. No commercial re-use. See rights and permissions. Published by BMJ.

${ }^{1}$ Institute for Sports Medicine, Alpine Medicine and Health Tourism, Tirol Kliniken GmbH, Natters, Tirol, Austria ${ }^{2}$ Institute for Sports Medicine, Alpine Medicine and Health Tourism, University for Health Sciences, Medical Informatics and Technology (UMIT), Hall, Tirol, Austria

Correspondence to Dr Arnold Koller; arnold.koller@tirol-kliniken.at
Alpine ski racing is a demanding and multifaceted sport requiring high levels of physical and technical competence. ${ }^{1}$ Because of the complexity of the sport, the selection of useful sport-specific tests of physiological capacities is challenging. ${ }^{1}$ Aerobic capacity is commonly measured using incremental cycle ergometer exercise, while anaerobic capacity is commonly tested using metabolically highly demanding all-out Wingate cycling. ${ }^{2}$ High aerobic/anaerobic capacity of an elite alpine skier is considered an important physiological determinant of competitive success. ${ }^{2}$ However, new findings on the molecular basis for exercise-induced fatigue do not support this assertion. ${ }^{3-6}$

The contractile function of skeletal muscle declines during intense or prolonged physical exercise, that is, fatigue develops. ${ }^{3}$ Within the muscle fibres, fatigue is generally related to increased energy demands, in which effective ATP resynthesis is needed to match the dramatically increased ATP consumption during contractions. ${ }^{3}$ In contracting muscle fibres, ATP is mainly consumed by actomyosin cross-bridges and the sarcoplasmic reticulum $\mathrm{Ca}^{2+}$ pumps. ${ }^{3}$ Adequate ATP delivery to the ATP-consuming proteins is essential for normal cell function and integrity. ${ }^{3}$ Obviously, mechanisms to prevent these catastrophic consequences of ATP depletion exist within the muscle fibres. ${ }^{3}$ These mechanisms involve, on the one hand, effective metabolic systems to resynthesise ATP and, on the other hand, a fatigue-induced decline in ATP consumption. ${ }^{3}$ The latter fatigue mechanisms, which inhibit contraction-dependent ATP consumption, are a major focus of a recent review. ${ }^{3}$ Examples of exercises in which different fatigue mechanisms might limit performance are given in table 1 of the review by Cheng et $a l^{3}$ Importantly, these different fatigue mechanisms might limit performance in metabolically demanding exercises.
For example, increased production of reactive oxygen/nitrogen species (ROS) and impaired cellular $\mathrm{Ca}^{2+}$ handling are implicated in prolonged force depression observed in skeletal muscle after metabolically highly demanding all-out Wingate cycling. ${ }^{4}$ Moreover, muscle biopsies taken 24 hours after high-intensity cycling exercise show an extensive fragmentation of the sarcoplasmic reticulum $\mathrm{Ca}^{2+}$ channels, the ryanodine receptor 1 (RyR 1$).{ }^{4}$ Interestingly, elite endurance athletes develop a prolonged force depression after metabolically highly demanding all-out Wingate cycling, but no ROS-dependent RyR1 fragmentation. ${ }^{4}$

By contrast, prolonged force depression after mechanically demanding eccentric contractions (100 drop jumps from a height of $0.5 \mathrm{~m}$ ) is largely independent of $\mathrm{Ca}^{2+}$ and ROS, and RyR1 fragmentation is observed in only some recreationally active elderly subjects. $^{5}$ However, the force depression was not more marked in these subjects. ${ }^{5}$ Moreover, force depression after mechanically demanding eccentric contractions are similar in both recreationally active subjects and endurance trained athletes, despite the antioxidant capacity being higher in endurance trained muscles. ${ }^{5}$ Thus, the mechanisms underlying prolonged force depression after mechanically demanding eccentric contractions are dissimilar to those after metabolically highly demanding all-out Wingate cycling.

In addition, eccentric muscle activity is a titin based and not an $\mathrm{O}_{2}$ ATP coupled contraction form. Shortly, when the sarcomeres of a skeletal muscle are stretched, for example, by gravitational forces, the titin immunoglobulin (Ig) domain segments and the PEVK region (The PEVK region is a titin spring element, which is rich in proline $(\mathrm{P})$, glutamate $(\mathrm{E})$, valine $(\mathrm{V})$, and lysine $(\mathrm{K})$ residues and is considered to be an intrinsically disordered protein region) extend. ${ }^{6}$ Titin domain folding against a force represents a potential source of work production in 
muscles, which presumably acts synchronously with the actomyosin contractile mechanism. ${ }^{6}$ This way, titin is an active component in the sarcomere that helps to maximise work output without consuming ATP. ${ }^{6}$ Titin as a force generating muscle protein is a major focus of a recent review. ${ }^{6}$ Titin Ig domain refolding under force as a source of work production speaks against ATP depletion as a central factor underlying the impaired contractile function after mechanically demanding eccentric contractions.

Alpine skiing can arguably be characterised as the only sport in which well-coordinated eccentric muscle action is the decisive element. ${ }^{7}$ Eccentric muscle contraction is essential for opposing the high centrifugal forces experienced by skiers in carved turns. ${ }^{7}$ Carved turns of successful skiers are characterised by a short and distinct eccentric steering phase. $^{7}$ Well-coordinated eccentric muscle activation is thus a key feature for success in competitive alpine skiing. ${ }^{7}$ Consequently, the mechanisms underlying force depression after ski racing are similar to those after mechanically demanding dropjump exercise. ${ }^{5}$

Fatigue develops rapidly during physical activities requiring a rate of ATP production that exceeds the aerobic capacity of the muscle fibres. ${ }^{3}$ This type of fatigue is closely related to the need for ATP production by anaerobic metabolism, ${ }^{3}$ for example, metabolically highly demanding all-out Wingate cycling. Anaerobic metabolism leads to accumulation of lactate and hydrogen ions and increased blood lactate concentrations were measured after alpine ski racing without affecting competitive performance. ${ }^{13}$ However, the high metabolic loads experienced by alpine skiers essentially stem from the simultaneous activation of a plethora of trunk muscles necessary to maintain core stability and balance. ${ }^{7}$ Moreover, a recent study shows that recreational alpine skiing is associated with prolonged eccentric quadriceps and hamstring fatigue. ${ }^{8}$ Interestingly, concentric types of endurance training (metabolically demanding exercises) (eg, biking) do not prevent fatigue during eccentric (ie, skiing) types of endurance exercise (mechanically demanding exercises). ${ }^{8}$

Based on these findings and in agreement with a recent study, we suggest that preseason aerobic and anaerobic tests are of limited use for prediction of alpine skiing performance. ${ }^{1}$ A valid and reliable test battery that can predict performance in alpine skiing seems to be lacking. Therefore, future research directed towards screening for valid components of athletic performance is required. ${ }^{1}$

Contributors AK and WS wrote this editorial.

Funding The authors have not declared a specific grant for this research from any funding agency in the public, commercial or not-for-profit sectors.

Competing interests None declared.

Patient consent for publication Not required.

Provenance and peer review Not commissioned; externally peer reviewed.

Open access This is an open access article distributed in accordance with the Creative Commons Attribution Non Commercial (CC BY-NC 4.0) license, which permits others to distribute, remix, adapt, build upon this work non-commercially, and license their derivative works on different terms, provided the original work is properly cited, appropriate credit is given, any changes made indicated, and the use is non-commercial. See: http://creativecommons.org/licenses/by-nc/4.0/.

\section{REFERENCES}

1. Nilsson R, Lindberg A-S, Theos A, et al. Aerobic variables for prediction of alpine skiing performance - a novel approach. Sports Med Int Open 2018;02:E105-12.

2. Ferland P-M, Comtois AS. Athletic profile of alpine Ski racers: a systematic review. J Stregth Cond Res 2018;32:3591-600.

3. Cheng AJ, Place N, Westerblad H. Molecular basis for exerciseinduced fatigue: the importance of strictly controlled Cellular $\mathrm{Ca}^{2+}$ handling. Cold Spring Harb Perspect Med 2018;8.

4. Place N, Ivarsson N, Venckunas T, et al. Ryanodine receptor fragmentation and sarcoplasmic reticulum $\mathrm{Ca}^{2+}$ leak after one session of high-intensity interval exercise. Proc Natl Acad Sci USA 2015;112:15492-7.

5. Kamandulis S, de Souza Leite F, Hernández A, et al. Prolonged force depression after mechanically demanding contractions is largely independent of $\mathrm{Ca}^{2+}$ and reactive oxygen species. Faseb $\mathrm{J}$ 2017;31:4809-20.

6. Hoppeler H. Eccentric exercise. Physiology and application in sport and rehabilitation. London: Routledge Research in Sport and Exercise Science, 2014: 138-44.

7. Freundt JK, Linke WA. Titin as a force generating muscle protein under regulatory control. J Appl Physiol;104.

8. Koller A, Fuchs B, Leichtfried V, et al. Decrease in eccentric quadriceps and hamstring strength in recreational alpine skiiers after prolonged skiing. BMJ Open Sport Exerc Med 2015;0:e000028. 